\title{
Smoke-free Legislation and Hospitalizations for Acute Coronary Syndrome
}

\author{
Jill P. Pell, M.D., Sally Haw, B.Sc., Stuart Cobbe, M.D., David E. Newby, Ph.D., \\ Alastair C.H. Pell, M.D., Colin Fischbacher, M.B., Ch.B., \\ Alex McConnachie, Ph.D., Stuart Pringle, M.D., David Murdoch, M.B., Ch.B., \\ Frank Dunn, M.D., Keith Oldroyd, M.D., Paul Maclntyre, M.D., \\ Brian O'Rourke, M.D., and William Borland, B.Sc.
}

ABSTRACT

From the University of Glasgow (J.P.P., S.C., A.M.), Southern General Hospital (D.M.), Stobhill Hospital (F.D.), Western Infirmary (K.O.), and Western General Hospital (W.B.) - all in Glasgow; University of Edinburgh (S.H., D.E.N.) and Information Services Division (C.F.) - both in Edinburgh; Monklands Hospital, Airdrie (A.C.H.P.); Ninewells Hospital, Dundee (S.P.); Royal Alexandra Hospital, Paisley (P.M.); and Hairmyers Hospital, East Kilbride (B.O.) - all in the United Kingdom. Address reprint requests to Dr. J. Pell at Rm. 305, Public Health Section, University of Glasgow, 1 Lilybank Gardens, Glasgow G12 8RZ, United Kingdom, or at j.pell@ clinmed.gla.ac.uk.

N Engl J Med 2008;359:482-91. Copyright @ 2008 Massachusetts Medical Society.

\section{BACKGROUND}

Previous studies have suggested a reduction in the total number of hospital admissions for acute coronary syndrome after the enactment of legislation banning smoking in public places. However, it is unknown whether the reduction in admissions involved nonsmokers, smokers, or both.

METHODS

Since the end of March 2006, smoking has been prohibited by law in all enclosed public places throughout Scotland. We collected information prospectively on smoking status and exposure to secondhand smoke based on questionnaires and biochemical findings from all patients admitted with acute coronary syndrome to nine Scottish hospitals during the 10-month period preceding the passage of the legislation and during the same period the next year. These hospitals accounted for $64 \%$ of admissions for acute coronary syndrome in Scotland, which has a population of 5.1 million.

RESULTS

Overall, the number of admissions for acute coronary syndrome decreased from 3235 to 2684 - a 17\% reduction (95\% confidence interval, 16 to 18) - as compared with a $4 \%$ reduction in England (which has no such legislation) during the same period and a mean annual decrease of 3\% (maximum decrease, 9\%) in Scotland during the decade preceding the study. The reduction in the number of admissions was not due to an increase in the number of deaths of patients with acute coronary syndrome who were not admitted to the hospital; this latter number decreased by $6 \%$. There was a $14 \%$ reduction in the number of admissions for acute coronary syndrome among smokers, a 19\% reduction among former smokers, and a $21 \%$ reduction among persons who had never smoked. Persons who had never smoked reported a decrease in the weekly duration of exposure to secondhand smoke $(\mathrm{P}<0.001$ by the chi-square test for trend) that was confirmed by a decrease in their geometric mean concentration of serum cotinine from 0.68 to 0.56 ng per milliliter $(\mathrm{P}<0.001$ by the t-test).

\section{CONCLUSIONS}

The number of admissions for acute coronary syndrome decreased after the implementation of smoke-free legislation. A total of $67 \%$ of the decrease involved nonsmokers. However, fewer admissions among smokers also contributed to the overall reduction. 
T

HE SMOKING, HEALTH AND SOCIAL CARE Act, which was passed in 2005, prohibited smoking in all enclosed public places and workplaces in Scotland after the end of March 2006. Smoke-free legislation aims to protect nonsmokers from secondhand smoke, but it may also reduce the risk among smokers because of reduced smoking or increased smoking cessation. ${ }^{1-4}$ Eight studies have shown reduced numbers of hospital admissions for acute coronary syndrome after the enactment of such legislation. ${ }^{5-12}$ These studies were limited by retrospective data collection, ${ }^{5-12}$ the use of clinical diagnostic labels, ${ }^{5-12}$ confounding by seasonal variations, ${ }^{7}$ and small numbers of patients. ${ }^{5,8,12}$ Only one study, involving 22 patients, included information on smoking status, ${ }^{12}$ and none included information on exposure to secondhand smoke. Therefore, the investigators were unable to show the extent to which the overall reduction in hospital admissions was due to protection from secondhand smoke. Our aim was to prospectively compare the number of admissions for acute coronary syndrome before and after implementation of national legislation, overall and according to smoking status.

\section{METHODS}

\section{SETTING}

Scotland has a population of 5.1 million. We collected data prospectively on all patients with acute coronary syndrome admitted to nine hospitals during the 10 months before implementation of the legislation (June 2005 through March 2006) and during the same 10 months thereafter (June 2006 through March 2007). The hospital catchment areas did not change; these areas accounted for $63 \%$ of admissions for acute coronary syndrome in Scotland before the legislation and 64\% of these admissions after the legislation. ${ }^{13}$ We compared two periods involving the same months of the year to rule out seasonal effects, and we examined the change in hospital admissions by month to ensure that the change was not due to an atypically hot or cold month.

\section{CASE ASCERTAINMENT}

The West Glasgow Research Ethics Committee approved the study, including access to case notes and specimens obtained from patients who died before recruitment. Acute coronary syndrome was defined as a detectable level of cardiac troponin after an emergency admission for chest pain. During the study periods, the troponin level was measured routinely in all patients admitted with chest pain. Therefore, our case definition could be applied consistently across all hospitals and patients, irrespective of day or time of admission or the unit to which the patient was admitted. To ensure complete case ascertainment, the hospital laboratories produced daily lists of troponin assays in patients who underwent those tests. Research nurses who were dedicated to the study identified all eligible patients and conducted structured interviews. Written, informed consent was obtained from all patients.

\section{SMOKING STATUS AND EXPOSURE TO SECONDHAND SMOKE}

The level of cotinine was measured in residual serum from clinical samples obtained on admission. All samples were centrifuged and stored locally at $-20^{\circ} \mathrm{C}$ and then transported on dry ice to a central laboratory (ABS Laboratory, London), where cotinine was assayed with the use of gas chromatography with a specific nitrogen phosphorus detector. ${ }^{14}$ Cotinine and the internal standard 5-methyl cotinine were extracted with the use of dichloroethane from $100-\mu$ l samples after alkalization with the use of sodium hydroxide. The lower limit of detection was $0.1 \mathrm{ng}$ per milliliter. Cotinine assays were used to validate self-reported smoking status and provide an objective measurement of exposure to secondhand smoke. Current smokers were defined as persons who classified themselves as being smokers and persons with a serum cotinine level of more than $12 \mathrm{ng}$ per milliliter. Persons who had never smoked were defined as persons who classified themselves as never having smoked and persons with a cotinine level of $12 \mathrm{ng}$ per milliliter or less. Former smokers were defined as persons who classified themselves as being former smokers and persons with cotinine levels of $12 \mathrm{ng}$ per milliliter or less. Nonsmokers comprised former smokers and persons who had never smoked.

\section{HISTORICAL AND GEOGRAPHIC COMPARISONS}

To account for unrelated lifestyle or treatment changes, we studied the historical trend in Scotland and contemporaneous data from England, which is similar with regard to demographic profile, lifestyle, climate, and free health care. The Scottish Morbidity Record 01 routinely collects in- 
formation on all hospital admissions, including the date and type of admission and disease codes. ${ }^{15}$ We used these data to determine trends in admissions for acute coronary syndrome (International Classification ofDiseases, 10th revision [ICD-10], code I21) in the preceding 10 years. Hospital Episode Statistics collects similar information in England, where legislation banning smoking in public places was not implemented until July 2007. ${ }^{16} \mathrm{We}$ used admissions for acute coronary syndrome (ICD-10 code I21) in England during the periods June 2005 through March 2006 and June 2006 through March 2007 as a geographic control. The General Registrar's Office for Scotland collates all death-certificate data, including date, place, and cause of death. ${ }^{17}$ We used these data to determine whether changes in the number of admissions could be explained by changes in the number of patients who died without being hospitalized.

\section{STATISTICAL ANALYSIS}

We analyzed the percentage reduction in the number of admissions, overall and according to smoking status, and we performed subgroup analyses according to the patients' sex and age group. We analyzed two groups of admissions: the first group included men 55 years of age or younger and women 65 years of age or younger, and the second group included older patients. Since the denominators for these reductions in admissions were random quantities, confidence intervals were derived from confidence intervals for the percentage of admissions during the two periods that occurred after enactment of the legislation. Assuming that the numbers of events before $\left(\mathrm{N}_{\text {pre }}\right)$ and after $\left(\mathrm{N}_{\text {post }}\right)$ legislation are Poisson random variables, the result of the equation $\mathrm{N}_{\text {post }}$ divided by the sum of $\mathrm{N}_{\text {post }}$ and $\mathrm{N}_{\text {pre }}$ will follow a binomial distribution. Transformation to an odds scale results in a confidence interval for $\mathrm{N}_{\text {post }}$ divided by $\mathrm{N}_{\text {pre }}$, from which a confidence interval for the percentage reduction can be derived.

In the absence of catchment-population denominators for subgroups of patients categorized according to smoking status, we were unable to determine a change in incidence. However, any population change would comprise a reduction in the number of smokers and an increase in the number of former smokers. Therefore, among former smokers, a reduction in the number of admissions will underestimate a reduction in incidence. Smoke-free legislation may reduce the prevalence of smoking in a population or the number of cigarettes smoked, but it will not alter the relative risk associated with smoking a given number of cigarettes. Among smokers, a decrease in prevalence would reduce the number of admissions but have no effect on incidence, and therefore, a change in the number of admissions is more meaningful than population-based incidence. The prevalence of smoking in a population of persons who had never smoked is unlikely to change in 1 year among patients in the age group at risk for acute coronary syndrome, since smoking usually commences at a much earlier age. Therefore, among persons who had never smoked, the percentage reduction in the numbers of cases of acute coronary syndrome will equate to the percentage reduction in the incidence of acute coronary syndrome.

Binary and ordinal data were compared with the use of chi-square tests and tests for trend, respectively. We applied two-sample t-tests to logarithmically transformed data on cotinine levels. Analyses were performed with the use of SPSS software for Windows, version 13.0 (SPSS).

\section{RESULTS}

\section{ADMISSIONS FOR ACUTE CORONARY SYNDROME}

Before enactment of the legislation banning smoking from public places, 3235 patients were admitted to the hospital for acute coronary syndrome. After enactment of the legislation, this number decreased by $17 \%$ ( $95 \%$ confidence interval [CI], 16 to 18 ), to 2684 . The number of monthly admissions during the whole period decreased; this decrease became more pronounced over time after the implementation of the legislation $(\mathrm{P}=0.02$ by the chi-square test for trend) (Fig. 1). In England, the number of admissions for acute coronary syndrome decreased by $4 \%$ during a similar period. In Scotland, the trend during the 10 years before legislation was a $3 \%$ mean annual reduction ( $95 \%$ CI, 3 to 4), with a maximum reduction of $9 \%$ in 2000; this reduction could not be attributed to the number of patients who were not hospitalized and who died from acute coronary syndrome. The number of patients who were not hospitalized and who died from acute coronary syndrome decreased by 6\%, from 2202 patients during the period 2005 through 2006 to 2080 patients during the period 2006 through 2007.

Of the 3235 patients with acute coronary syn- 


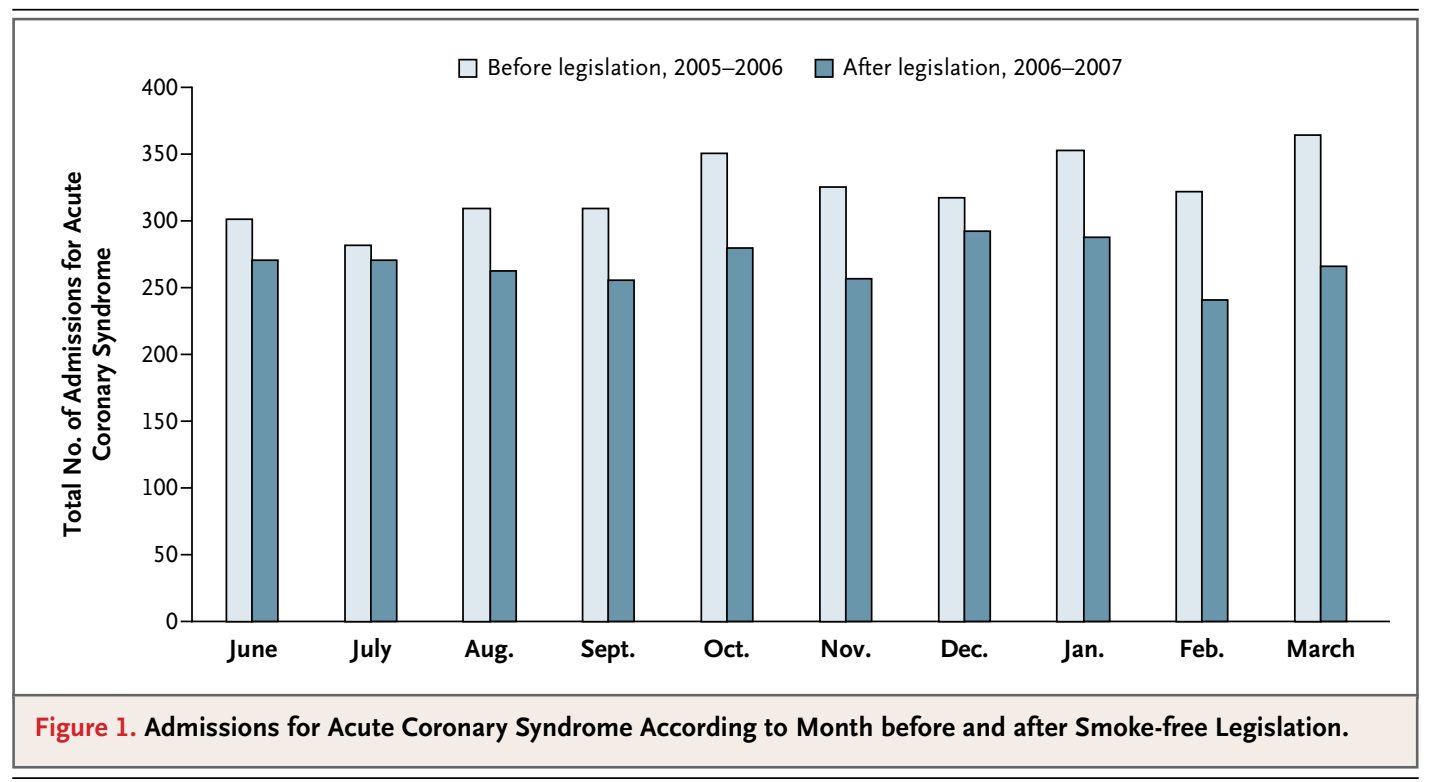

drome admitted to the hospital before enactment of the legislation, 2806 (87\%) provided written informed consent to participate in the study, 252 $(8 \%)$ were unable to provide written informed consent, and 177 (5\%) declined to participate. Of the 2684 patients with acute coronary syndrome admitted to the hospital after enactment of the legislation, $2322(87 \%)$ consented, $207(8 \%)$ were unable to consent, and 155 (6\%) declined. Therefore, the same percentage of patients provided information during both periods $(\mathrm{P}=0.80$ by the chi-square test). Among smokers, the number of admissions decreased by 14\% (95\% CI, 12 to 16), from 1176 to 1016. The number of admissions among former smokers decreased from 953 to 769 (19\%; 95\% CI, 17 to 21), and the number of admissions among persons who had never smoked decreased from 677 to 537 (21\%; 95\% CI, 18 to 24) (Table 1). Therefore, $67 \%$ of the admissions prevented after the enactment of legislation involved nonsmokers.

Among current smokers, the reduction was greater among women (19\%; 95\% CI, 15 to 23$)$ than among men (11\%; $95 \%$ CI, 9 to 13 ) (Table 1). Similarly, there was a greater decrease among women who were nonsmokers (23\%; 95\% CI, 20 to 26) than among men who were nonsmokers (18\%; 95\% CI, 16 to 20). Among current smokers, the decrease was lower among men 55 years of age or younger and women 65 years of age or younger ( $9 \%$; $95 \%$ CI, 6 to 12) than among older patients (18\%; 95\% CI, 15 to 21) (Table 1). The same was true for nonsmokers ( $8 \%$ [95\% CI, 4 to 12], vs. $22 \%$ [95\% CI, 20 to 24]).

\section{EXPOSURE TO SECONDHAND SMOKE}

Among nonsmokers, 1614 (99\%) provided information on their exposure to secondhand smoke before enactment of the legislation, and 1285 (98\%) provided information about exposure after enactment. The correlation between cotinine and the self-reported duration of exposure to secondhand smoke was similar before $(r=0.33, P<0.001)$ and after $(r=0.33, P<0.001)$ enactment of the legislation. The percentage of persons who had never smoked who reported no exposure to secondhand smoke increased from $57 \%$ to $78 \%(\mathrm{P}<0.001)$ (Table 2), largely because of reduced exposure to smoke in pubs, bars, and clubs. The percentage of persons who reported no exposure to smoke in these locations increased from $77 \%$ to $96 \%$ $(\mathrm{P}<0.001)$ (Table 2). Self-reported reductions in exposure to smoke were confirmed by a reduction in the geometric mean level of serum cotinine from 0.68 to $0.56 \mathrm{ng}$ per milliliter $(\mathrm{P}<0.001)$. Former smokers also reported reduced exposure to smoke (Table 2). The geometric mean level of cotinine in these persons decreased from 0.71 to 0.57 ng per milliliter $(\mathrm{P}<0.001)$. Before the legislation was enacted, men who were nonsmokers had the same geometric mean level of cotinine as women (i.e., $0.66 \mathrm{ng}$ per milliliter). After the legislation was enacted, this level decreased by $38 \%$, 


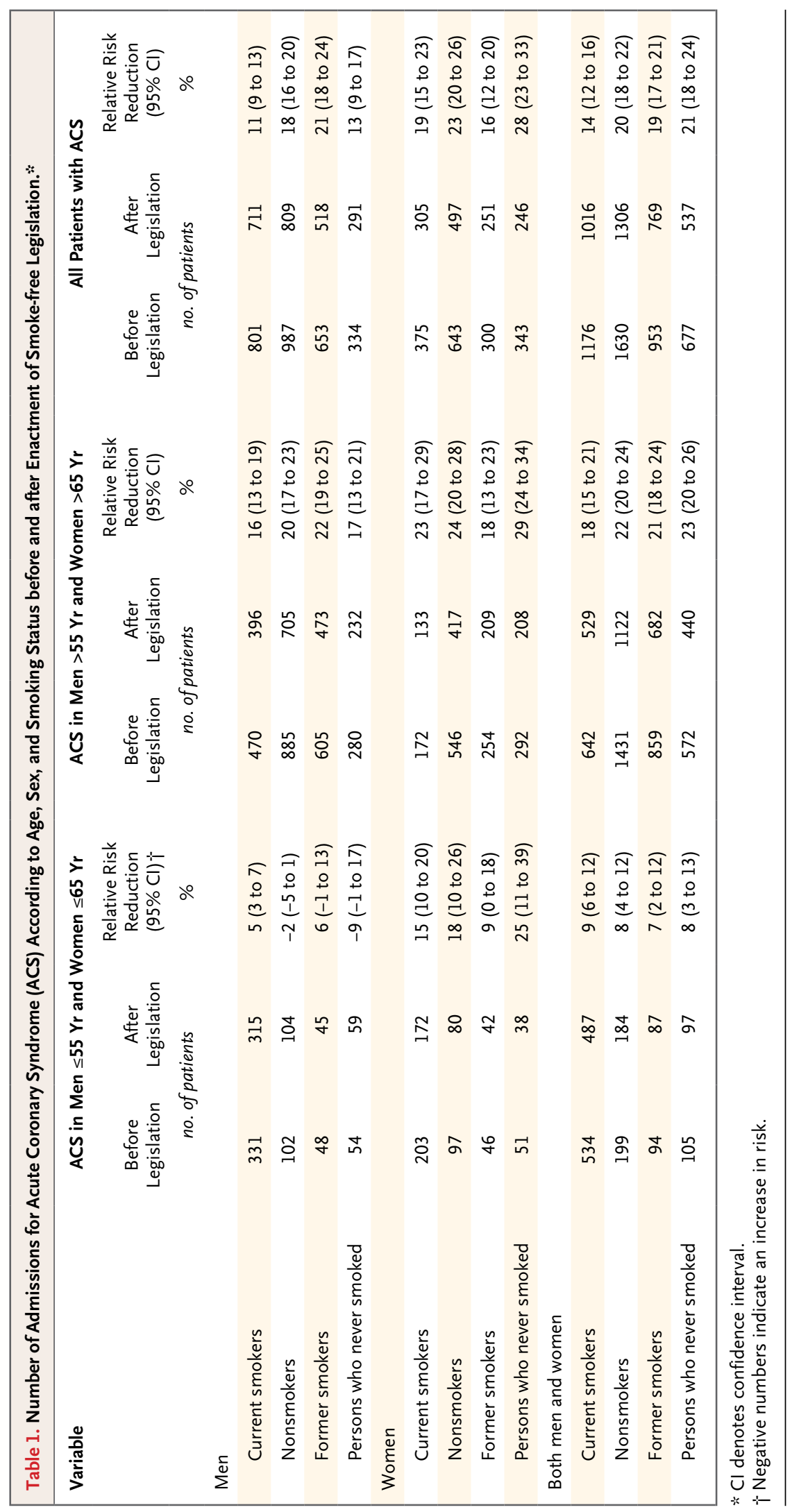




\begin{tabular}{|c|c|c|c|c|c|c|}
\hline \multirow[t]{3}{*}{$\begin{array}{l}\text { Location and No. } \\
\text { of Hours }\end{array}$} & \multicolumn{3}{|c|}{ Former Smokers } & \multicolumn{3}{|c|}{ Persons Who Never Smoked } \\
\hline & $\begin{array}{l}\text { Before } \\
\text { Legislation } \\
(\mathrm{N}=937)\end{array}$ & $\begin{array}{l}\text { After Legislation } \\
\qquad(\mathrm{N}=748)\end{array}$ & P Value* & $\begin{array}{c}\text { Before } \\
\text { Legislation } \\
(\mathrm{N}=677)\end{array}$ & $\begin{array}{l}\text { After Legislation } \\
\qquad(\mathrm{N}=537)\end{array}$ & P Value* \\
\hline & \multicolumn{2}{|c|}{ no. (\%) } & \multicolumn{4}{|c|}{ no. (\%) } \\
\hline \multicolumn{7}{|l|}{ Own home } \\
\hline $0 \mathrm{hr}$ & $778(83)$ & $635(85)$ & 0.39 & $565(83)$ & $460(86)$ & 0.64 \\
\hline $1-5 \mathrm{hr}$ & $71(8)$ & $48(6)$ & & $41(6)$ & $18(3)$ & \\
\hline$\geq 6 \mathrm{hr}$ & $88(9)$ & $65(9)$ & & $71(10)$ & $59(11)$ & \\
\hline \multicolumn{7}{|c|}{ Other people's homes } \\
\hline $0 \mathrm{hr}$ & $860(92)$ & $698(93)$ & 0.42 & $617(91)$ & $495(92)$ & 0.34 \\
\hline $1-5 \mathrm{hr}$ & $64(7)$ & $38(5)$ & & $34(5)$ & $28(5)$ & \\
\hline$\geq 6 \mathrm{hr}$ & $13(1)$ & $12(2)$ & & $26(4)$ & $14(3)$ & \\
\hline \multicolumn{7}{|l|}{ Work } \\
\hline $0 \mathrm{hr}$ & $902(96)$ & 740 (99) & $<0.001$ & $640(95)$ & 519 (97) & 0.04 \\
\hline $1-5 \mathrm{hr}$ & $21(2)$ & $6(1)$ & & $15(2)$ & $5(1)$ & \\
\hline$\geq 6 \mathrm{hr}$ & $14(1)$ & $2(0)$ & & $22(3)$ & $10(2)$ & \\
\hline \multicolumn{7}{|l|}{ Pubs, bars, or clubs } \\
\hline $0 \mathrm{hr}$ & 709 (76) & 737 (99) & $<0.001$ & $522(77)$ & $515(96)$ & $<0.001$ \\
\hline $1-5 \mathrm{hr}$ & 174 (19) & $4(1)$ & & $107(16)$ & $8(1)$ & \\
\hline$\geq 6 \mathrm{hr}$ & $54(6)$ & $7(1)$ & & $48(7)$ & $14(3)$ & \\
\hline \multicolumn{7}{|c|}{ Cars, buses, or trains } \\
\hline $0 \mathrm{hr}$ & 918 (98) & 733 (98) & 0.74 & 644 (95) & 519 (97) & 0.33 \\
\hline $1-5 \mathrm{hr}$ & $14(1)$ & $13(2)$ & & $32(5)$ & $18(3)$ & \\
\hline$\geq 6 \mathrm{hr}$ & $5(1)$ & $2(0)$ & & $1(0)$ & $0(0)$ & \\
\hline \multicolumn{7}{|l|}{ Other public places } \\
\hline $0 \mathrm{hr}$ & $826(88)$ & 733 (98) & $<0.001$ & $579(86)$ & $518(96)$ & $<0.001$ \\
\hline $1-5 \mathrm{hr}$ & $91(10)$ & $15(2)$ & & $66(10)$ & $8(1)$ & \\
\hline$\geq 6 \mathrm{hr}$ & $20(2)$ & $0(0)$ & & $32(5)$ & $11(2)$ & \\
\hline \multicolumn{7}{|l|}{ All locations } \\
\hline $0 \mathrm{hr}$ & 489 (52) & 589 (79) & $<0.001$ & $385(57)$ & $418(78)$ & $<0.001$ \\
\hline $1-5 \mathrm{hr}$ & $231(25)$ & $89(12)$ & & $177(26)$ & $49(9)$ & \\
\hline$\geq 6 \mathrm{hr}$ & $217(23)$ & $70(9)$ & & 115 (17) & $70(13)$ & \\
\hline
\end{tabular}

*P values were calculated using the chi-square test for trend.

to 0.41 ng per milliliter in men $(\mathrm{P}<0.001)$, and by $47 \%$, to 0.35 ng per milliliter in women $(\mathrm{P}<0.001)$. Among the admissions for acute coronary syndrome involving men 55 years of age or younger and women 65 years of age or younger, the geometric mean level of cotinine decreased $34 \%$, from 0.90 to $0.59 \mathrm{ng}$ per milliliter $(\mathrm{P}<0.001)$. Among older patients, it decreased $42 \%$, from 0.62 to 0.36 ng per milliliter $(\mathrm{P}<0001)$.
Overall, cotinine concentrations decreased less among patients with acute coronary syndrome than among persons in the general population. Among nonsmokers with acute coronary syndrome, the geometric mean level of serum cotinine decreased $18 \%$, from 0.68 to $0.56 \mathrm{ng}$ per milliliter. Among nonsmokers 45 years of age or older in the general population, the geometric mean level of cotinine in saliva was lower in both 
periods but decreased by $42 \%$, from 0.43 to 0.25 ng per milliliter. ${ }^{14}$ The percentage of people with a cotinine concentration of more than $0.7 \mathrm{ng}$ per milliliter decreased more among patients with acute coronary syndrome (from $42 \%$ to $9 \%$, $\mathrm{P}<0.001)$ than among persons in the general population (from $35 \%$ to $26 \%, \mathrm{P}=0.02$ ).

Among smokers admitted to the hospital because of acute coronary syndrome, there was no significant reduction in the self-reported number of cigarettes smoked or the geometric mean level of cotinine (from 152 to 147 ng per milliliter; $\mathrm{P}=0.72$ ); the cotinine level among smokers in the general population decreased from 167 to $103 \mathrm{ng}$ per milliliter. ${ }^{18}$

DISCUSSION

We found a $17 \%$ reduction in the number of hospital admissions for acute coronary syndrome after enactment of smoke-free legislation; this reduction was greater than the underlying trend and the contemporaneous change in a neighboring country without such legislation. The number of prevented admissions involving nonsmokers accounted for $67 \%$ of the reduction.

Early compliance with the Scottish legislation was high. ${ }^{19}$ Two weeks after implementation of this legislation, the levels of secondhand smoke in bars had decreased by $86 \%$. Concerns about displacement of smoking from public places into homes have not been realized. The results of cotinine assays in schoolchildren ${ }^{20}$ and adults who are nonsmokers ${ }^{18}$ have confirmed a reduced overall exposure to smoke. In the adult population of nonsmokers in Scotland, cotinine concentrations have decreased by $42 \%$, similar to the $47 \%$ reduction after the enactment of smoke-free legislation in New York. ${ }^{21}$ In our study, nonsmokers with acute coronary syndrome who were admitted to hospitals had higher cotinine concentrations than persons in the general population; these findings are consistent with secondhand smoke being a risk factor for acute coronary syndrome. Our difference is an underestimate, since the level of cotinine was measured in serum and saliva, and the values from saliva specimens are $25 \%$ higher than those from serum. ${ }^{22}$ The decrease in the cotinine concentration among nonsmokers with acute coronary syndrome who were admitted to the hospital was less than that in the general population; this finding is consistent with admissions being prevented through the protection of persons who were previously exposed to secondhand smoke. The percentage of nonsmokers with very high cotinine concentrations decreased more among persons who were admitted to the hospital than among the general population, suggesting that the number of events prevented among persons with a very high exposure to smoke before the enactment of the legislation was disproportionately high.

The excess risk of acute coronary syndrome associated with smoking decreases within days after smoking cessation, and it is reduced by $50 \%$ at 1 year. ${ }^{23,24}$ The primary aim of smoke-free legislation is to protect nonsmokers from secondhand smoke. However, studies in other countries suggest that anticipation of legislation also encourages reduced smoking and cessation among smokers. $^{1-4,24,25}$ In the 3 months before the enactment of the legislation in Scotland, the number of telephone calls to smoking-cessation services was $67 \%$ higher than it was in the subsequent 3 months. ${ }^{26}$ The lack of reduced cotinine concentrations among smokers who were admitted to the hospital is not surprising, since admissions were prevented among persons who reduced the number of cigarettes smoked. These smokers contribute to a decrease in the cotinine concentration in the population but not to the decrease in the number of hospital admissions.

One Italian study suggests reductions in acute coronary syndrome among persons 60 years of age or younger, but not among older patients. ${ }^{7}$ A subsequent Italian study reported reductions in both age groups. ${ }^{10}$ In Scotland, we observed an $8 \%$ reduction ( $95 \%$ CI, 6 to 10) in acute coronary syndrome among men who were 55 years of age or younger and women 65 years of age or younger as compared with a $20 \%$ reduction $(95 \%$ CI, 18 to 22) in admissions involving men who were older than 55 years of age and women who were older than 65 years of age. The age effect was apparent among both smokers and nonsmokers. Among nonsmokers, younger patients had a higher baseline cotinine concentration but a similar reduction in acute coronary syndrome (38\% vs. $42 \%)$. Caution should be heeded in extrapolating the effects of age and sex to a population in another country. Culture and climate may produce demographic differences in smoking patterns in the home, public places, and outdoor spaces.

Our study suggests that the reduction in acute 
coronary syndrome among nonsmokers may be greater among women than among men. Exposure to smoke may have decreased more among women; among nonsmokers, the cotinine concentration decreased by $37 \%$ in men and $47 \%$ in women. Alternatively, a similar reduction in exposure to secondhand smoke may produce a greater effect in women than in men. Acute coronary syndrome is caused by thrombus formation at the site of a disrupted atherosclerotic plaque. Plaque rupture is the most common cause of this syndrome, although thrombus formation on an eroded plaque is particularly common in women. ${ }^{27}$ Although some risk factors for acute coronary syndrome, such as dyslipidemia, predispose to plaque rupture, smoking increases the risk through acute thrombosis. ${ }^{28}$ Hence, the relative risk associated with smoking is greater among women than among men and is associated with a steeper dose response. ${ }^{29}$

Three studies have examined local legislation banning smoking in public places in geographically isolated communities. Sargent et al. showed a $40 \%$ reduction (95\% CI, 1 to 79 ) in the number of hospital admissions for myocardial infarction among the 68,140 inhabitants of Helena, Montana, as compared with a nonsignificant increase in hospital admissions involving patients living outside Helena. ${ }^{5}$ This study comprised only 64 admissions over 12 months. Pechacek and Babb suggested that a $40 \%$ reduction in hospital admissions was implausible, and they calculated 19\% as the theoretical maximum reduction achievable through a reduction in exposure to secondhand smoke. ${ }^{30}$ Khuder et al. showed a 39\% reduction in hospital admissions after enactment of smokefree legislation in Bowling Green, Ohio, which has a population of less than $30,000 .^{8}$ Among residents of Pueblo, Colorado, which has a population of 148,000 , the number of hospital admissions for myocardial infarction decreased by $27 \%$, as compared with a $15 \%$ decrease among nonresidents who were admitted to the same hospital and a $3 \%$ decrease in another city without such legislation. ${ }^{6}$

The number of admissions for acute coronary syndrome decreased by $13 \%$ after the enactment of smoke-free legislation in Saskatoon, SK, Canada, which has a population of $220,000^{11}$; this finding is concomitant with a $25 \%$ reduction in the prevalence of smoking (from $24 \%$ to $18 \%$ ). A modest $8 \%$ reduction in the prevalence of smoking occurred in New York because of local and partial restrictions (i.e., restrictions in some public places but not in others) during the 8-year period before enactment of statewide smoke-free legislation and because of an atypically low baseline level of exposure to smoke. ${ }^{9}$ The investigators estimated that the reduction in prevalence would have been $19 \%$ if the local restrictions had not occurred. Barone-Adesi et al. compared the number of hospital admissions for myocardial infarction before and after enactment of smoke-free legislation in Piedmont, Italy, with the number of admissions during the same periods in the previous year. ${ }^{7}$ The number of admissions decreased among patients who were 60 years of age or younger (odds ratio, 0.89; 95\% CI, 0.81 to 0.98 ), but not among older patients. In Rome, which has a population of 2.7 million, acute coronary events decreased by $7.9 \%$ among persons 65 to 74 years of age (95\% CI, 3.4 to 12.2 ) and by $11.2 \%$ among younger patients (95\% CI, 6.9 to 15.3). ${ }^{10}$

All studies to date were retrospective and used clinical diagnostic labels. The studies described above did not include information on smoking status or exposure to secondhand smoke, and the investigators were unable to determine whether the overall reduction in hospital admissions involved nonsmokers or smokers. Only one previous study included information on smoking status. Seo and Torabi reported a $71 \%$ reduction in the number of admissions to Bloomington Hospital in Bloomington, Indiana, because of acute coronary syndrome among self-reported nonsmokers, from 17 admissions during the 22-month period before the enactment of smoke-free legislation to 5 admissions during the 22-month period after the legislation. ${ }^{12}$ There was a nonsignificant $11 \%$ reduction in admissions to a control hospital. There was no reduction in the number of admissions among smokers ( 8 vs. 7). The investigators were unable to corroborate self-reported smoking status on the basis of biochemical tests.

A meta-analysis of four early studies reported a pooled relative-risk estimate of $0.73 .{ }^{31}$ Later studies have provided lower effect estimates, but the 95\% confidence intervals associated with the pooled estimate ( 0.56 to 0.89 ) nonetheless were consistent with the $17 \%$ overall reduction in hospital admissions that we observed. Between-country differences are inevitable because of different levels of baseline exposure to smoke.

Our study has a number of strengths. The nine 
hospitals served a population of more than 3 million. We ascertained the number of admissions prospectively using a standard definition that included confirmation based on biochemical tests. We linked our data to the Scottish Morbidity Record 01 database. Only $52 \%$ of our subjects received a clinical diagnosis of ICD-10 code I21 (acute myocardial infarction), with no difference in the diagnosis between the two study periods (1966 diagnoses [52\%] vs. 1663 diagnoses [51\%]). The remainder received uninformative codes: predominantly I251 (atherosclerotic disease), I200 (unstable angina), R074 (chest pain, unspecified), and I248 (other forms of acute ischemic heart disease); these findings highlight the limitations of retrospective studies with the use of routine data. We had information on both the underlying trend before the study and the contemporaneous change in a neighboring country. We collected detailed information prospectively on smoking and exposure to secondhand smoke using both questionnaires and biochemical assays.

Further studies are required to determine whether the early improvements will be sustained.
Smokers who quit may subsequently relapse. Conversely, changing social attitudes may discourage young people from beginning to smoke, producing an additional benefit in the future. Our overall results are consistent with those of other studies. The World Health Organization's Framework Convention on Tobacco Control is the first international legal treaty to focus on improving public health. ${ }^{32}$ In Article 8, the signatories commit to protect the public from exposure to secondhand smoke. Our findings provide support for the treaty.

Supported by a National Health Service Health Scotland project grant and salary support from the British Heart Foundation.

Dr. Dunn reports receiving grant support from Atherogenics, Merck Sharp and Dohme, and Novartis. Dr. Oldroyd reports receiving consulting fees from Medtronic and Cordis and stock options from Medtronic. No other potential conflict of interest relevant to this article was reported.

We thank Judith Anderson, Anne Andrews, Sharon Cameron, Jackie Dougall, Carole Gibson, Joanne Kelly, John Rodgers, Karen Smith, Fiona Stevenson, Helen Waldie, Ann Wright, and Jim Young for collecting data; James Burns, Ann Cruikshank, Callum Fraser, Jacqueline McGuire, Elliott Simpson, Peter Stromberg, and Simon Walker for accessing samples; and the Wellcome Trust Clinical Research Facility (Edinburgh) and ABS Laboratory (London).
REFERENCES

1. Fichtenberg CM, Glantz SA. Association of the California Tobacco Control Program with declines in cigarette consumption and mortality from heart disease. N Engl J Med 2000;343:1772-7.

2. Hopkins DP, Briss PA, Ricard CJ, et al. Reviews of evidence regarding interventions to reduce tobacco use and exposure to environmental tobacco smoke. Am J Prev Med 2001;20:Suppl:16-66.

3. Chapman S, Borland R, Scollo $M$, Brownson RC, Dominello A, Woodward S. The impact of smoke-free workplaces on declining cigarette consumption in Australia and the United States. Am J Public Health 1999;89:1018-23.

4. Heloma A, Jaakkola MS. Four-year follow-up of exposure, attitudes and smoking behaviour following enactment of Finland's national smoke-free work-place law. Addiction 2003;98:1111-7.

5. Sargent RP, Shepard RM, Glantz SA. Reduced incidence of admissions for myocardial infarction associated with public smoking ban: before and after study. BMJ 2004;328:977-80.

6. Bartecchi C, Alsever RN, Nevin-Woods $\mathrm{C}$, et al. Reduction in the incidence of acute myocardial infarction associated with a citywide smoking ordinance. Circulation 2006;114:1490-6.
7. Barone-Adesi F, Vizzini L, Merletti F, Richiardi L. Short-term effects of Italian smoking regulation on rates of hospital admission for acute myocardial infarction. Eur Heart J 2006;27:2468-72.

8. Khuder SA, Milz S, Jordan T, Price J, Silvestri K, Butler P. The impact of a smoking ban on hospital admissions for coronary heart disease. Prev Med 2007; 45:3-8.

9. Juster HR, Loomis BR, Hinman TM, et al. Declines in hospital admissions for acute myocardial infarction in New York State after implementation of a comprehensive smoking ban. Am J Public Health 2007;97:2035-9.

10. Cesaroni G, Forastiere F, Agabiti N, Valente P, Zuccaro P, Perucci CA. Effect of Italian smoking ban on population rates of acute coronary events. Circulation 2008 117:1183-8.

11. Lemstra M, Neudorf C, Opondo J. Implications of a public smoking ban. Can J Public Health 2008;99:62-5.

12. Seo DC, Torabi MR. Reduced admissions for acute myocardial infarction as sociated with a public smoking ban: matched controlled study. J Drug Educ 2007;37:217-26.

13. Coronary heart disease statistics. Edinburgh: NHS National Services Scotland,
2007. (Accessed July 7, 2008, at http://www. isdscotland.org/isd/2421.html.)

14. Feyerabend C, Russell MA. A rapid gas-liquid chromatographic method for the determination of cotinine and nicotine in biological fluids. J Pharm Pharmacol 1990;42:450-2.

15. Acute myocardial infarction: trends in incidence 1996-2005. Table IC2. Edinburgh: NHS National Services Scotland, 2007. (Accessed July 7, 2008, at http:// www.isdscotland.org/isd/files/oct06_IC2. xls.)

16. Hospital episode statistics. London: Department of Health, 2007. (Accessed July 7, 2008, at http://www.dh.gov.uk/en/ Publicationsandstatistics/Statistics/ HospitalEpisodeStatistics/index.htm.) 17. Deaths: information and statistics. Edinburgh: General Register for Scotland, 2007. (Accessed July 7, 2008, at http://www. gro-scotland.gov.uk/statistics/deaths.html.) 18. Haw SJ, Gruer L. Changes in exposure of adult non-smokers to secondhand smoke after implementation of smokefree legislation in Scotland: national cross sectional survey. BMJ 2007;335:549.

19. Semple S, Creely KS, Naji A, Miller BG, Ayres JG. Secondhand smoke levels in Scottish pubs: the effect of smoke-free legislation. Tob Control 2007;16:127-32. 
20. Akhtar PC, Currie DB, Currie CE, Haw SJ. Changes in child exposure to environmental tobacco smoke (CHETS) study after implementation of smoke-free legislation in Scotland: national cross sectional survey. BMJ 2007;335:545.

21. Reduced secondhand smoke exposure after implementation of a comprehensive statewide smoking ban - New York, June 26, 2003-June 30, 2004. MMWR Morb Mortal Wkly Rep 2007;56:705-8.

22. Jarvis MJ, Primatesta P, Erens B, Feyerabend $\mathrm{C}$, Bryant A. Measuring nicotine intake in population surveys: comparability of saliva cotinine and plasma cotinine estimates. Nicotine Tob Res 2003;5:349-55.

23. Law MR, Wald NJ. Environmental tobacco smoke and ischemic heart disease. Prog Cardiovasc Dis 2003;46:31-8.
24. Fichtenberg CM, Glantz SA. Effect of smoke-free workplaces and smoking behaviour: systematic review. BMJ 2002;325: 188.

25. Brownson RC, Hopkins DP, Wakefield MA. Effects of smoking restrictions in the workplace. Annu Rev Public Health 2002; 23:333-48.

26. National smoking cessation monitoring database. Edinburgh: NHS National Services Scotland, 2007. (Accessed July 7, 2008, at http://www.isdscotland.org/isd/ 4647.html.)

27. Davies MJ. The pathophysiology of acute coronary syndromes. Heart 2000;83: 361-6.

28. Burke AP, Farb A, Malcom GT, Liang $\mathrm{YH}$, Smialek J, Virmani R. Coronary risk factors and plaque morphology in men with coronary disease who died suddenly. N Engl J Med 1997;336:1276-82.

29. Njølstad I, Arnesen E, Lund-Larsen PG. Smoking, serum lipids, blood pressure, and sex differences in myocardial infarction: a 12-year follow-up of the Finnmark Study. Circulation 1996;93:450-6.

30. Pechacek TF, Babb S. How acute and reversible are the cardiovascular risks of secondhand smoke? BMJ 2004;328:980-3. 31. Dinno A, Glantz S. Clean indoor air laws immediately reduce heart attacks. Prev Med 2007;45:9-11.

32. WHO Framework Convention on Tobacco Control (WHO FCTC). Geneva: World Health Organization, 2005. (Accessed July 7, 2008, at http://www.who.int/ tobacco/framework/en/.)

Copyright (๑) 2008 Massachusetts Medical Society.

FULL TEXT OF ALL JOURNAL ARTICLES ON THE WORLD WIDE WEB

Access to the complete text of the Journal on the Internet is free to all subscribers. To use this Web site, subscribers should go to the Journal's home page (www.nejm.org) and register by entering their names and subscriber numbers as they appear on their mailing labels. After this one-time registration, subscribers can use their passwords to log on for electronic access to the entire Journal from any computer that is connected to the Internet. Features include a library of all issues since January 1993 and abstracts since January 1975, a full-text search capacity, and a personal archive for saving articles and search results of interest. All articles can be printed in a format that is virtually identical to that of the typeset pages. Beginning 6 months after publication, the full text of all Original Articles and Special Articles is available free to nonsubscribers. 